\title{
THE TRANSITION FORM QUANTUM TO CLASSICAL ELECTRON TRANSPORT IN PALLADIUM FILMS OF NANOMETER THICKNESS
}

\author{
Z. Stasyuk, M. Kozak, B. Penyukh, R. Bihun \\ Ivan Franko National University of Lviv, Chair of General Physics, \\ 50 Drahomanov Str., Lviv, UA-79005, Ukraine
}

(Received July 27, 2002)

\begin{abstract}
In ultrahigh vacuum conditions the electrical conductivity of thin palladium films was investigated. The resistivity dependences of thin film's thickness were explained in the framework of Quantum and Classical size-effect theories. The average amplitude of one-dimentional surface asperities was estimated from the results of electrical measurements.
\end{abstract}

Key words: thin metallic films, quantum and classical size-effect.

PACS number(s): 72.10.-d; 73.25.+i; 73.61.-r

According to the classical theory [1] of electron transport in thin metallic films the residual resistivity $\rho_{\mathrm{r}}$ due to the surface scattering is proportional to the film's inverse thickness $d^{-1}$ :

$$
\rho_{\mathrm{r}}=\left(\rho(d)-\rho_{\infty}\right)=\frac{3 l}{8 d} \rho_{\infty} \sim d^{-1},
$$

where $l$ is the mean free path of electron, $\rho(d)$ is the resistivity of the film with the thickness $d$ and $\rho_{\infty}$ is the resistivity of the infinitely thick film $(d \rightarrow \infty)$ which possesses the same structure as the film with the thickness $d$. In (1) it is supposed that the surface scattering of electrons is diffuse. The experimental results for the relatively thick films may be explained in the framework of this theory. The experimental criterion [2] of using this theory is $d \geq(0.1 \div 0.2) l$.

On the other hand, the condition for observing quantum regime of electron transport when translated in terms of length becomes $d<\pi l$ with $l=\tau v_{\mathrm{F}}$, where $v_{\mathrm{F}}$ is the Fermy velocity of electron and $\tau$ is its relaxation time due to scattering [3]. In the framework of quantum theory of electron transport in thin metallic films the residual resistivity of thin film is proportional to $d^{-\alpha}$ :

$$
\rho_{r}=\left(\rho(d)-\rho_{\infty}\right) \sim d^{-\alpha},
$$

where $2.1 \leq \alpha \leq 6$ [4]

The quantum theories of electron transport also assume the presence of oscillations in $\rho(d)$ with the period of $d_{0}=\lambda / 2$, where $\lambda$ is the electron de Broglie wavelength. Experimentally the resistance oscillations were not often observed due to the influence of the film's surface imperfections and due to the insufficient sensitivity of the film's thickness measurements. The presence or the absence of $\rho(d)$ oscillations may be caused by the film's growth dynamic particularities [5].

The transition from the quantum regime to the classical regime of electron transport in very thin palladium films $(d<50 \mathrm{~nm})$ was investigated in this paper. The experiment was carried out under ultrahigh vacuum con- ditions in evacuated glass chamber. The films were deposited onto polished and fused glass plates by thermal evaporation. To prevent coagulation the films were condensed onto cooled to $78 \mathrm{~K}$ substrates with the rate deposition equal to $0.01 \mathrm{~nm} / \mathrm{sec}$. The film's resistance during the deposition was measured by digital ohmmeter and then registered by computer. The film's thickness was monitored by quartz microbalance with the sensitivity which was not worse than $0.2 \mathrm{~nm}$. The other experimental details were described in our previous papers (for example, $[6,7]$ ). It must be mentioned that the films obtained by this experimental method were fine grained [6].

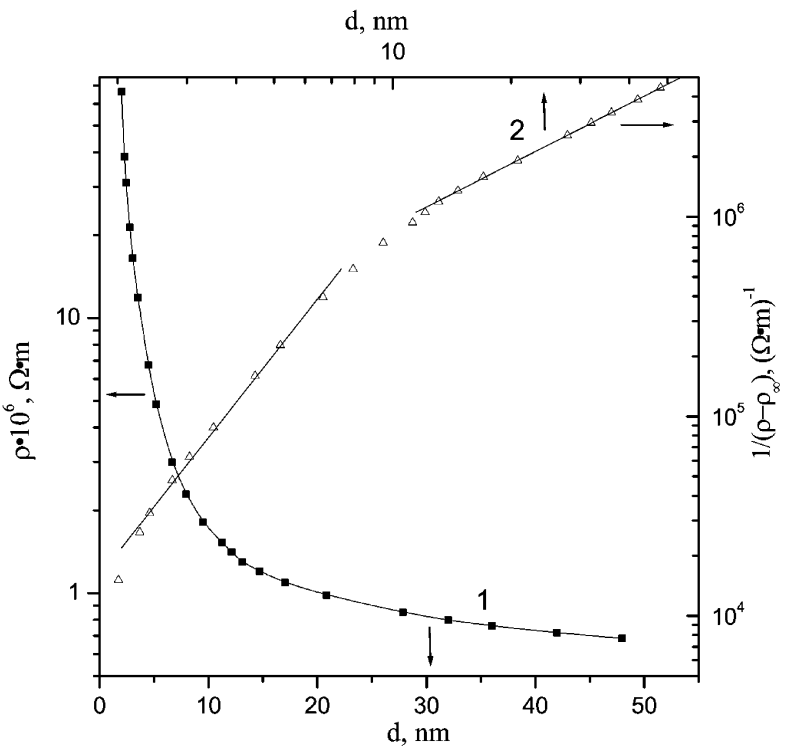

Fig. 1. The resistivity $\rho$ and the inverse residual resistivity $\left(\rho-\rho_{\infty}\right)^{-1}$ as functions of the film thickness $d$.

All the resistance measurements were carried out at $T=78 \mathrm{~K}$. The percolation threshold was fixed on resistance level $10^{8} \Omega$ and it was observed at $d=1 \mathrm{~nm}$. The curve 1 in Fig. 1 shows that the film's resistivity $\rho(d)$ 
changes as their thickness $d$ increases. Curve 2 is plotted in common logarithmic scale for inverse residual resistivity $\left[\rho(d)-\rho_{\infty}\right]^{-1}$ size dependence. The $\rho_{\infty}$ value was found as the slope of the linear part of $\rho(d) d=f(d)$ experimental dependence $[1,7]$. It is clear that curve 2 has two linear parts. At the large thickness region $(d>20 \mathrm{~nm})$ the slope of straight line segment is equal to 1 , and in the small thickness region the slope of the next straight line segment is equal to 2.4. The intermediate thickness region may be described in the framework of $[8,9]$ classical theory developed for polycrystalline films with the heterogeneous cross section. According to [8] the size dependence of thin film's resistivity may be expressed by:

$$
\rho(d)=\rho_{\infty}\left[1-\left(\frac{h}{d}\right)^{2}\right]^{-1 / 2}\left[1+\frac{3 \lambda}{8 d}\left[1-\left(\frac{h}{d}\right)^{2}\right]^{-1}\right]
$$

where $h$ is the average amplitude of one-dimensional surface asperities. The dependence $\rho(d) d=f(d)$ is shown in Fig. 2. The experimental data are indicated by points and the theoretical curve calculated from (3) at $h=3 \mathrm{~nm}$ is performed as a solid line. The value $h=3 \mathrm{~nm}$ found from this dependence coordinates in a good way to $h=2 \div 3 \mathrm{~nm}$, measured in our thin films STM tests.

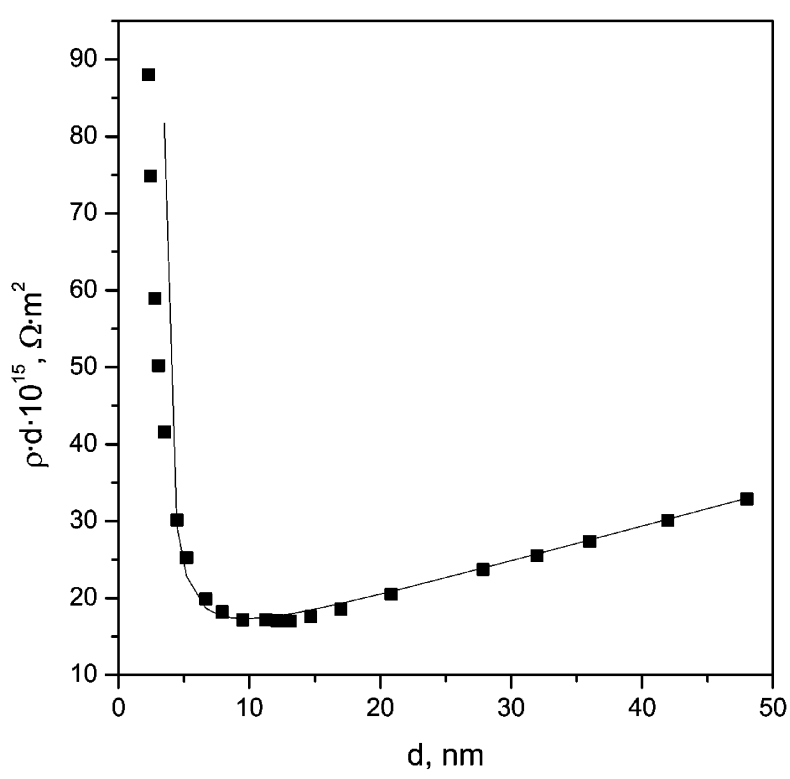

Fig. 2. The dependence $\rho(d) d$ on $d$.

Finally, we are able to conclude that the resistivity size dependence $\rho(d)$ of very thin electrically continuous metallic films may be described successfully by combining the quantum [4] and the classical theories $[1,8]$ of size effects.
[1] E. H. Sondheimer, Adv. Phys. 1, 1 (1952).

[2] G. Wedler, N. Fouwad, Z. Phys. Chem. BRD 40, 1 (1964).

[3] N. Trivedi, N. W. Ashcroft, Phys. Rev. B 38, 12298 (1988).

[4] G. Fishman, D. Calecki, Phys. Rev. Let. 62, 1302 (1989).

[5] G. Palasantzas, J. Th. M. De Hosson, Phys. Rev. B 63,
125404 (2001).

[6] B. L. Melnichuk, A. I. Lopatinsky, Z. V. Stasyuk, Phys. Status Solidi (a) 171, 495 (1999).

[7] K. G. Lakh, Z. V. Stasyuk, Ukr. Phys. J. 39, 739 (1994).

[8] Y. Namba, Jpn. J. Appl. Phys. 9, 1326 (1970).

[9] Z. Stasyuk, J. Phys. Stud. 3, 102 (1999).

\section{ПЕРЕХІД ВІД КВАНТОВОГО ДО КЛАСИЧНОГО ЕЛЕКТРОННОГО ПЕРЕНОСУ У ПЛІВКАХ ПАЛАДІЮ НАНОМЕТРОВӦ̈ ТОВЩИНИ}

3. В. Стасюк, М. М. Козак, Б. Р. Пенюх, Р. І. Бігун

Львівсъкий національний університет імені Івана Франка, вул. Драгоманова, 50, Львів, 79005, Украӥна

В умовах надвисокого вакууму досліджено електричну провідність дуже тонких паладієвих плівок. Отримані розмірні залежності питомого опору плівок пояснено в межах теорій квантового та класичного розмірних ефектів. На основі експериментальних даних зроблено оңінку макроскопічної неоднорідности товшини плівок. 